\title{
Quaternary lava tubes distribution in Jeju Island and their potential deformation risks
}

Jungrack Kim ${ }^{* 1}$, Shih-Yuan Lin ${ }^{2}$, Jong-woo $\mathrm{Oh}^{3}$

$5 \quad{ }^{1}$ Department of Geoinformatics, University of Seoul

Seoulsiripdaero 163., Dongdaemum-gu, Seoul,130-743, Korea; Tel: + phone (+82) 07082533008

${ }^{2}$ Department of Land Economics, National Chengchi University

No. 64, Section 2, Zhinan Road, Wenshan District, Taipei City, Taipei, Taiwan

${ }^{3}$ Korean Speleological Society

120, Neungdong-ro, Gwangjin-gu, Seoul,08381 Korea

Correspondence to: Jungrack Kim (kjrr001@gmail.com)

ABSTRACT. Jeju Island, located in the southern sea of the Korean Peninsula, is a volcanic island created by the tertiary and quaternary volcanic eruptions. A group of lava tubes formed between quaternary lava flows constitutes one of the most 15 predominant geological contexts owing to its unique and complex network, for which a total of 178 lava tubes is estimated. As a significant portion of lava caves have not been discovered, the threat caused by lava cave collapse has become one of the major concerns in connection with the recent infrastructure construction in Jeju Island. Considering the risk potential, the overall distribution and collapsing risk of the Jeju lava tube network were investigated in this study. Through spatial analysis, we firstly found that the lava tubes distribution is not correlated with specific geological units. Secondly, the risk of collapse is high especially when there are ongoing artificial constructions around the undisclosed lava tube network. We therefore introduced Interferometric Synthetic Aperture Radar (InSAR) techniques to measure the deformation of the ground surface where lava tube networks distributed underground. InSAR results and the proposed machine learning applications identified that the populations of ground deformations was up to $1-2 \mathrm{~mm} / \mathrm{year}$ and was inferred to be caused by the instability of the shallow lava cavity. Given that underground cavities could pose serious risks, a detailed physical exploration and threat assessment of potential cave groups is required before intensive anthropogenic construction is developed. 


\section{Introduction}

Lava tube is known as one of the most representative geomorphic features in volcanic landscape and the major consequences

of the lava flow formation. Pioneering works have been accomplished to confirm the origin of lava tubes in Hawaii volcanoes (Greeley, 1987; Greeley, 1971, 1972), Mt. Etna (Calvari and Pinkerton, 1998) and elsewhere. Along with geomorphic interpretation (Hwang et al., 2005; Valerio et al., 2010), numerical modelling of strain (Merle, 2000) and thermal erosion (Kerr, 2001; Bussey et al., 1997) established the outline of lava tube development. Based on the studies listed above, two scenarios for understanding lava tube development processing were established. First, the solidified lava roof blocked the liquid lava flow and a single structured lava tube was created. Second, the repetitive contraction of lava evolved into a multi-structured lava tube. (Kempe, 2009;Kempe et al., 2010). Recent research of lava tube has focused on comparative analyses, as the lava tube of solid planet/satellites identified by the spotting of skylight (Whittaker, 2012; Witter and Harris, 2007) are now proposed as a highly critical habitable environment.

Jeju Island, located on the southern coast of Korean Peninsular provides a valuable testbed for the geological/geomorphic 40 studies of lava tubes due to their high spatial density, unique diversity of cave morphology (Kempe and Woo, 2016) induced in deformation modes and easy accessibility (Woo et al., 2019). Indeed, the lava tube group in Jeju Island possess highly unique characteristics such as 200 more founded tubes in $1850 \mathrm{~km}^{2}$, population of long lava tubes up to $4-11 \mathrm{~km}$ and a variety of cave structures presenting all sorts of development stages (Son, 2019). The significance of Jeju lava tubes is that they occurred along shallow lava flows and there is a risk of cave deformation and collapse (Kim, 2006). With a further inspection,

45 lava tubes are distributed along the gentle slopes of Jeju Island, and some are close to dense human settlements. Furthermore, it is estimated that a large number of lava tubes that have never been disclosed have already collapsed. For instance, investigations conducted over decades showed that a large portion of the newly discovered lava caves on Jeju Island has been partially collapsed (Son, 2016). The risks involving potential lava tubes in Jeju Island were observed by Waltham and Park (2002), especially the cases of road-cave crossing. Based on the observations mentioned above, ground stability should be inspected before anthropogenic activities such as infrastructure construction. Take the ongoing construction of the second international airport in western Jeju Island as the example, the identification of potential lava tubes is hence highly critical to avoid risk induced by undiscovered cavities.

To achieve this, we tracked deformation caused by undiscovered lava tube network using Interferometric Synthetic Aperture Radar (InSAR) technology and spatial analysis method. Various technical approaches such as geological mapping and related spatial analysis were used together to improve the interpretation of line-of-sight (LOS) measurements of InSAR time series analysis on specific risky points. Such integrated approach was proposed to classify the actual deformed signal caused by lava tube instability, which is referred to as lava tube induced deformation point (LTDP). The applications of this study is not only 
limited to the assessment of the risks provoked by lava tube instability, but is of potential to be extended to identify the lava

60 tube development, which has become a significant interest in terms of the planetary habitat environment.

In such context, we firstly introduced the characteristics of the target area together with data sets in section 2 . The methodology details were introduced in section 3. The outputs from InSAR deformation analyses were interpreted in section 4 and the further discussion and conclusions were presented in section 5 .

65 2. Test site and data sets

2.1 Geological background of lava caves

The entire Jeju Island was investigated in this study as lava tubes were distributed throughout the island as shown in Fig. 1. The United Nations Educational, Scientific and Cultural Organization (UNESCO) has evaluated the unique geological landscape and designated nine geological attractions in 2010 and three more in 2014. Among them, the presences of lava tubes and involved cone volcanoes are highly distinguished. Up to now, there is still an ongoing discussion regarding the geological origin and processes of Jeju Island. Based on the conventional volcanic eruptions theory, the whole Jeju Island is considered as a single shield volcanic body (Kim and Choi, 2012). While another theory was developed to assess Jeju Island as a basaltic volcanic zone (Brenna et al., 2011; Brenna et al., 2012a; Brenna et al., 2012b). According to a study conducted by Koh et al.

75 (2013), Jeju Island was formed based on the accumulation of outpoured lavas and volcanoclastic erupted from a polygenetic composite volcano of Mt. Halla and numerous monogenetic volcanoes. The materials were intercalated or underlain by Seoguipo Formation (KIGAM, 2000). Koh et al. (2013) proposed a new genetic model of the volcanism in Jeju Island on the basis of borehole logging and interpretation of stratigraphy from over 100 exploratory boreholes (drilled at $<$ elevation $600 \mathrm{~m}$ since 2001), rock composition and age dating of volcanic rocks from both 686 recovered cores out of 78 boreholes and 74 outcrop sites. The geologic structure indicated that the activity of alkali basaltic lava effusion on land started about 1 Ma years ago and continued until Holocene. Which was also reported in Koh et al. (2008), Koh and Park (2010b) and Koh and Park (2010a). Koh et al. (2013) strongly exhibited the post-depositional volcanic activities are defined as extensive volcanic activities on land after the termination of sedimentation of Seogipo Formation since about $0.5 \mathrm{Ma}$. Such studies conclusively proposed that volcanic eruptions during the period from $0.3 \mathrm{Ma}$ to $0.1 \mathrm{Ma}$ must have shaped the body of Jeju Island. Also volcanic eruptions occurred from $0.1 \mathrm{Ma}$ to the Holocene have constructed the present topography of Jeju Island with various types of the volcanic tubes. In fact, the rocks distributed at lowerland areas in the eastern and western regions are predominantly transitional basalts, tholeiitic basalts and andesites in composition, compared with those in the northern and southern regions. Those petrological evidences proposed that lava tubes were primarily due to volcanic activities in 1.88 0.5 Ma and postdepositional period (0.5 Ma Holocene) (Kim and Lee, 2000; Sohn and Park, 2004; Koh et al., 2013). Therefore it implied that 
90 the lava flow inducing tubes might be originated from geological units especially with the quaternary basalt originated from a large number of cone volcanoes (see Figure 1 (a)). Although the number of lava tubes is different and gradually increased according to surveying works, Jeju volcanic island exhibited more than 179 well-documented lava tubes, including 144 lava tubes and 35 sea caves since Feb. 2016 (Son, 2016). The number of the 122 caves among 179 were scattered in eastern (22\%) and western areas (51\%) of Jeju city and the eastern of Seogwipo city (19\%). It was noted that a total of 178 lava tubes was identified in Jeju Island in the recent research conducted by Son (2019).

According to the geological map produced by KIGAM (2000), the rocks that make up Jeju Island are conglomerate, for which volcanic rocks were formed by lava eruption, and volcaniclastic rocks were formed by volcanic eruptions. Conglomerate is composed of nitrile sedimentary rock, conglomerate, and concave conglomerate confined between lava flows. Volcanic rocks are classified as basalt, rough basalt, basaltic rough andesite, rough andesite, and rough rocks. Some rough rocks show intrusive

100 shapes to form high terrain. Basalt is low-viscosity at the time of the eruption, and is covered with a large area to create a smooth terrain and distributed on the east and west sides of Jeju Island. Therefore it has been proved that the lava tubes exist with only basalt low-viscosity lava flow, so-called pahoehoe lava (see Q1 unit in Fig. 1 (b)). However, with the progressive discovery of lava tubes since 1990 somehow conflicted with such findings. Some major lava tubes cross the basaltic andesite lava flow, so-called 'a'ā lava which is presented as Q2 in Fig. 2 and has far higher viscosity. A sequence of studies speculated

105 the creation process of Jeju lava tubes involving its geological contexts (Kempe and Woo, 2016; Hwang et al., 2005; Son, 2009).

Results conducted by Son (2009) showed that 27 among the 37 examined lava tubes faced severe collapse and destroyed problems. Most lava tubes in Jeju island show that the internal and/or external failure and destroyed problems resulted from disconnected lava tubes. The investigation was conducted on 27 out of 179 roads over the lava tube. A total of 122 crossroads

110 over caves was scattered in eastern (37) and western areas (62) of Jeju city and the eastern of Seogwipo city (23). Results showed that 37\%, for instance Sunggul, Cheamchongul, Chogiwatgul, Jungryugul, Bangdyi cave, Manjang cave, Yongchun cave, Susan cave, Michun cave, Bilraemot cave, Bullalit cave of the 27 examined lava tubes faced serious collapse and destroyed problems. Moreover, 55 crossroads located over six natural monument caves out of 27 caves already had lava tube problems that are urgently required to take actions to protect citizen from the cave tours. Thus, a series of practice was required

115 to address the issue regarding abundant collapsed and destroyed lava tubes, including 1) the safe policy for roads over tubes; 2) the geophysical engineering survey with 27 lava tubes on the mega-sized construction sites; 3) the Cave Geographic Information Systems (CGIS) implementation for the systematic operation and management, and 4) the safe guide panel posted on the dangerous sites in Jeju Island. 


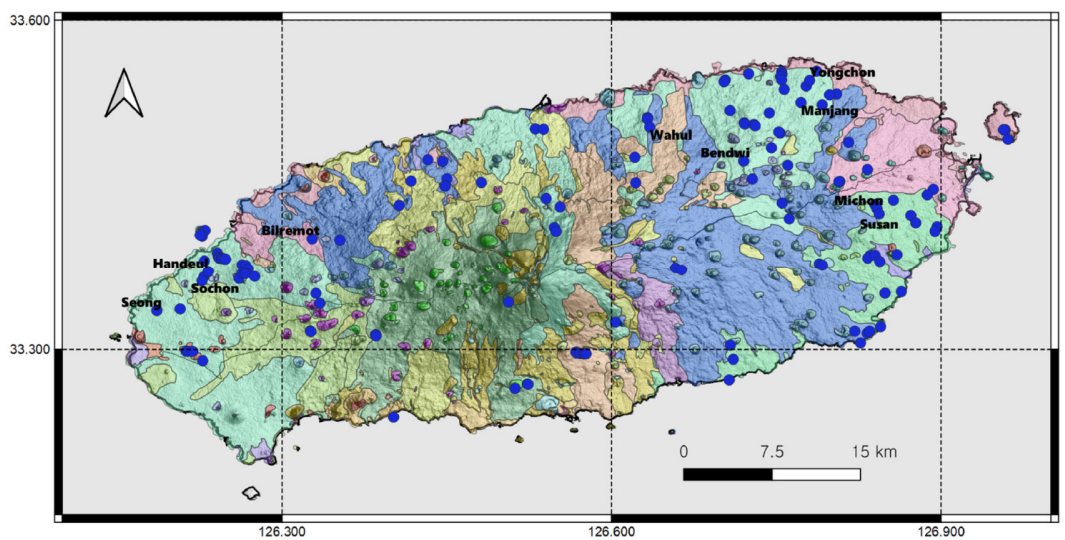

- Lava caves

Geological units

Seogwipo Formation

$\square$ Trachyandesite
Trachyandesite cinder cone

$\square$ Trachyande

Trachyte Cinder cone

Basall-trachyte(I)Tuff

Basalt-trachyte(II)

Basalt-trachyte(II) Cider cone

Basalt-trachyte(III)

- Basalt-trachyte(IV)
Basalt-trachyte $(Y)$

Basalt-trachyte(V) Cider Cone

Basalt-trachyte(VI)

Basaldrachye(VI) Cider Cone

- Basalt-trachyte(VIII)

Basalt-trachyte(VIII) Cider Cone

Basalt-trachyte $(V I I I)$

- Basalt-trachyte(VIII) Cider Cone
Bathyte(VIII) Tuff

$\square$ Sediment
Basalt(I)

$\square$ Basalt(I) Tuff

Basalt(II) Cider Cone

Basalt(III) Cider Cone
Basalt(III)

Basalt(IIII) Cider Cone

(b)

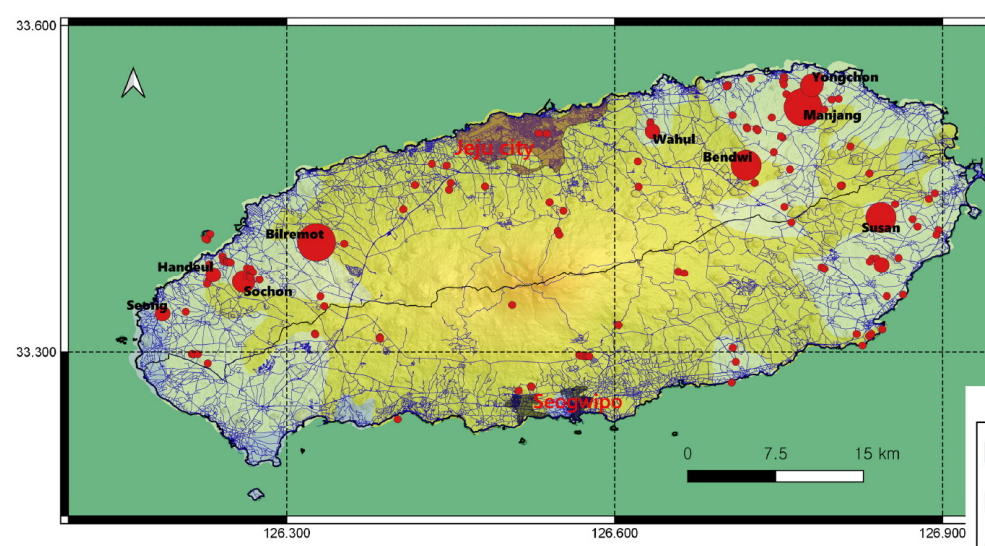

Figure 1: Geological context and lava caves of Jeju Island. (a) Lava tubes in detailed geological units associated with cinder cones and lava flows. (b) Lava tubes distributions, bedrock geological and road networks.

\subsection{Data sets}

For this study, it is necessary to carry out the detailed topographic data analyses for tracing of surface deformation as well as subsurface structures. The technology of space geodesy, such as InSAR data interpretation, are being widely used to replace 
conventional surveys to observe minor surface migration over a long period of time. Those have been successfully exploited for the detection of underground stability caused by depressurization, cavity creations and subtle surface creep (Baer et al., 2018; Intrieri et al., 2015; Hooper et al., 2004; Yun et al., 2019). Thus we expected the surface deformation on shallow lava tubes and cavities in Jeju Island are in the scope of InSAR observation accuracy estimated to a few millimetres. For InSAR processing, the optimal data set is Sentinel-1 SAR imagery (Geudtner et al., 2014) as the following bases. First, it is freely available on the public domain, Sentinel data hub. Second, images have been acquired by two SAR-satellite constellations, Sentinel 1A and 1B operating from 2015 and 2016 respectively. Therefore the Sentinel-1 constellation provided the shortest revisiting time ( $>6$ days) among all available InSAR assets. Third, their unique Interferometric Wide-swath mode (IW) operation with Terrain Observation and Progressive Scans SAR (TOPSAR) imaging makes available precise monitoring of the target area with a moderate spatial resolution ( $20 \mathrm{~m}$ in azimuth and a $4 \mathrm{~m}$ in range) and $250 \mathrm{~km}$ wide swath coverage (Geudtner et al., 2014). Especially its C-band wavelength guarantees relatively minor ionospheric errors carrying longwavelength artifacts compared to L-band InSAR. Since the estimated surface deformation over lava tubes is insignificant compared to the external error components, we were obliged to use InSAR time series analysis to obtain the displacement velocity. In terms of image availability, the image connection geometry in Sentinel-1 InSAR descending modes can be readily constructed covering sufficient period as shown in Fig. 2. It is worthwhile noting that, in order to achieve a comprehensive observation, we employed a strategy combining two different InSAR time-series analysis techniques, one is Persistent Scatterers (PS) to monitor the temporal migration on specific scatterers, such as crossing points of roads and lava tubes. Another method adopted is Small Baseline Subset (SBAS), which is for the extraction of regional deformation patterns. To 145 achieve sufficient InSAR pair stacks, PS analysis was constructed to cover a two year period with 75 images (Fig. 2(a)), while SBAS network was built on 13 images covering a half year period as shown in Fig. 2(b). The required number of InSAR pairs is usually higher in PS processing. SBAS was mainly introduced to observe regional characteristics compared to PS analysis. Thus a selection of 13 SBAS images for a half year fits the purpose. Basic characteristics of Sentinel-1 imagery are summarized in Table 1.

Table 1. Characteristics of employed Sentinel-1 images.

\begin{tabular}{l|l|l}
\hline & PS mode processing & SBAS mode processing \\
\hline Image number & 77 & 13 \\
\hline Master image & 2017.10 .04$. & 2017.10 .04$. \\
\hline Time coverage & $2016.01 .01-2018.12 .22$. & $2017.06 .20-2017.11 .11$. \\
\hline Heading angle (deg) & & -167.107 \\
\hline Incidence angle (deg) & \multicolumn{2}{|c}{44.0} \\
\hline Relative Orbit & \multicolumn{2}{|c}{134} \\
\hline Acquisition time & \multicolumn{2}{|c}{$06: 32$ KST (GMT+9) } \\
\hline
\end{tabular}



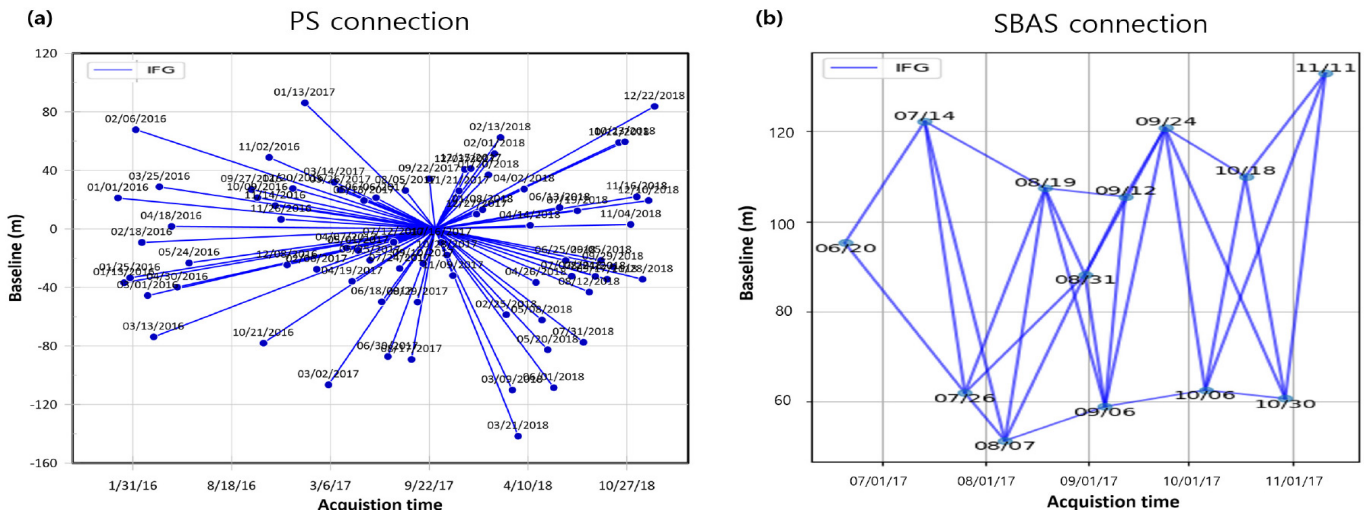

Figure 2: Connection graphs of employed Sentinel-1 InSAR pair as shown in (a) 72 descending images which are employed for PS time series analysis. (b) 13 descending images for SBAS analysis.

Another highlight of this study is that a few subsurface morphologies in lava tubes were established by 3D laser scanning to demonstrate their stability. Laser scanning was conducted using FARO Focus3D X330 laser scanner and GPS receiver. Point density of laser scanning was set as $15 \mathrm{~mm}$. A number of targets were pre-installed to be used as a joint point for data merging and also as an inspection point. The targets were installed without interfering with the point cloud acquisition inside the cave. Once the scanned was finished, the scanned point cloud collected in multiple stations were merged to form one complete model in the FARO SCENE 5.4 data post-processing software. Given the parameters such as the number of points, the number of repetitions and the search range, the registration error value was calculated within $\pm 2 \mathrm{~mm}$. After then, noise removal and georeferencing were performed based on ground control points to construct a fully co-registered 3D cave model for three lava caves.

\section{Results}

\subsection{Spatial analysis of lava tube distributions}

In spite of long historical research works, the distribution pattern of lava tubes still remains unclear. One clue to reveal the pattern is an involvement with low viscosity lava flow so called pahoehoe lava (Ahn and Hwang, 2009). However, as shown in Fig. 1, the spatial extent of pahoehoe lava flow and distribution of lava tubes are not highly correlated. Therefore, we tried to constrain the potential distribution of lava tubes using other evidences. We created the density map of lava tubes (178 in 
total) with the weighted values of their lengths and the co-kriging interpolation as shown in Fig. 3(b). The other useful information to spot the subsurface lava cavity is the existence of a geological feature so-called Sumgol, which assigns the collapsing place of lava cavity or the vertical joints or cracks over lava flows (Hamm et al., 2005). It is presumably related to the distribution of undiscovered lava tubes. We digitized the Sumgols and applied the distance transformation with the city block sampling method (Huang and Mitchell, 1994) as shown in Fig. 3(d). The convolution of two spatial distributions was proposed as the representation of subsurface cavities by lava flow (refer Fig. 8(a)). The convolution is corresponding to simple adding of the two materials as we do not apply any weighting. The gridded data sets assigned the distribution of Sumgol and the footprints of lava tubes were employed for the further processing of InSAR data sets as a constraint. The other data sets extracted from the geospatial information were used for the ground truth and validation. The details were described in section 4.
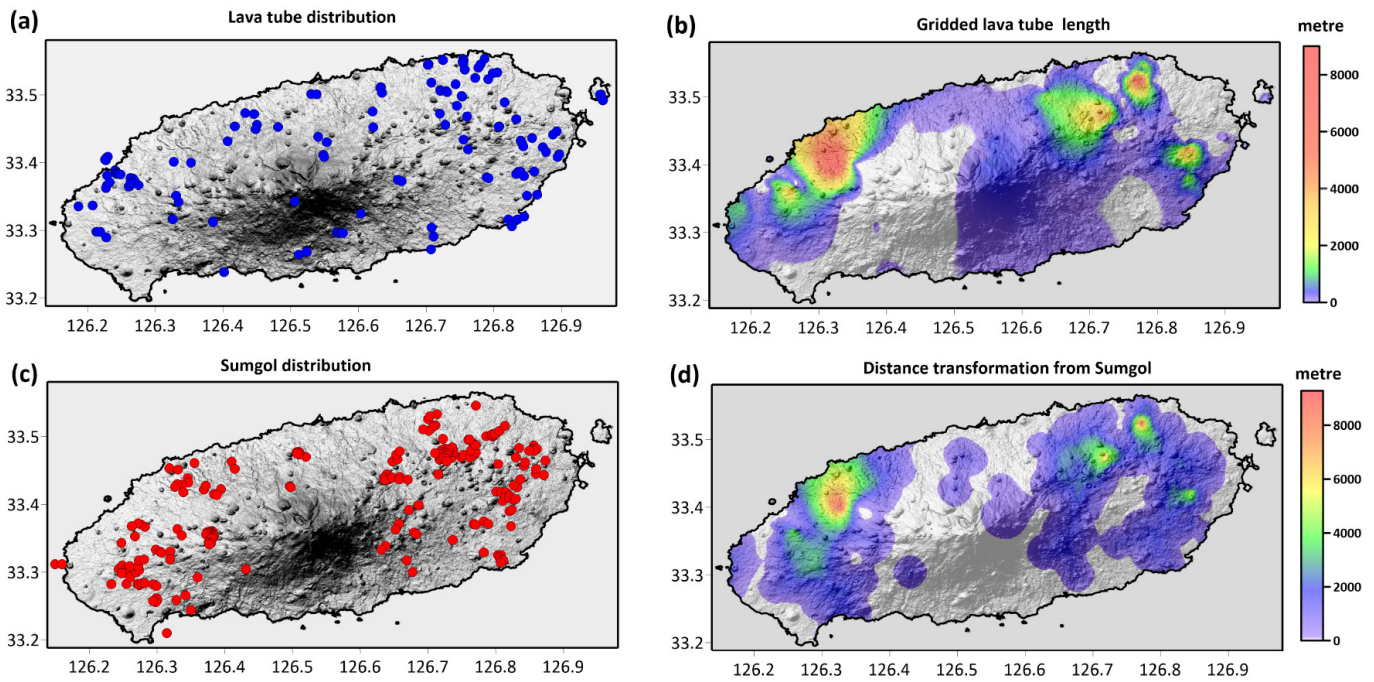

Figure 3: Spatial analyses to create processing mask. (a) Lava tube distributions and (b) density map of lava tubes calculated weighted their lengths. (c) Sumgol distributions and (d) distance transformation map of Sumgol.

\subsection{InSAR processing}

Although InSAR techniques have been effectively used for natural and artificial surface deformation observations, land surface monitoring caused by instability on the subsurface cavity would be a challenge of InSAR techniques due to the expected low 
deformation rate. There are two InSAR time series analysis algorithms commonly applied, including PS and SBAS approaches. The PS method exploits strong scatterers in time series interferograms, which are paired by a common master image and sufficient number of slave images (Ferretti et al., 2001; Ferretti et al., 2000). Compared with the PS approach, the SBAS technique (Berardino et al., 2002) determines all the appropriate InSAR pair subsets possessing a small baseline. In this study we employed PS and SBAS to respectively perform a long-term pointwise observation and short-term regional observations. An improved SBAS technique, New-SBAS (NSBAS), was employed to enhance the performance. The algorithmic improvements of time series analysis mainly aim for the densification of reliable scatterers and the capabilities have been proven.

According to a preliminary PS InSAR analysis, it was indicated that the temporal and spatial baseline conditions between SAR images in this study were adequate to address technical challenges with a standard PS algorithm, as shown in Fig. 2(a). The observations and error component terms to be handled in algorithms of time series analyses is expressed as follows:

$$
\begin{aligned}
& \Delta \varphi_{\text {obs }}=\Delta \varphi_{\text {Dint }}+\Delta \varphi_{\text {atm }}+\Delta \varphi_{\text {orb }}+\Delta \varphi_{\text {topo }}+\Delta \varphi_{\text {ion }}+\varphi_{\text {noise }} \\
& \Delta \varphi_{\text {Dint }}=\Delta \varphi_{\text {int }}-\varphi_{\text {topo }}
\end{aligned}
$$

where $\Delta \varphi_{o b s}$ is the phase difference of interferogram, $\Delta \varphi_{\text {Dint }}$ is the phase difference only by target topography, $\Delta \varphi_{o r b}$ is the phase difference by inaccurate orbital information, $\Delta \varphi_{\text {topo }}$ is the phase difference by inaccurate base topography, $\varphi_{\text {noise }}$ is the other phase noise, $\Delta \varphi_{a t m}$ is the phase difference by atmospheric phase components, and $\Delta \varphi_{i o n}$ is the phase difference caused by delay in the ionosphere.

The core idea of PS algorithm is to discriminate Persistent Scatterers with constant responses for amplitude dispersion and to

210 address the error estimations using iterative non-linear equations. Although PS required a large number of image stacks, the accuracy of InSAR deformation is up to $1 \mathrm{~mm}$ /year (Crosetto et al., 2016). On the contrary, PS algorithm is often suffered by the lack of observation density. Thus some PS variants were often introduced. In this study, the target area is full with stable rock scatterers. We therefore are able to employ the conventional PS algorithm to observe the temporal migration with high precision. It was also observed that the density of extracted scatterers was sufficient for further interpretation. Refer to Fig.

215 4(a) which shows the LOS displacements extracted via the PS time series analysis in the target area. The stable reference point which is as the standard for measuring relative deformations was carefully chosen based on the stability and dispersion of phase coherence and deformation rate. The time series displays of LOS surface deformations demonstrate that the deformation patterns along geological/landcover units were consistent overall. However, there were discrepancies between a few geological units and LOS deformations, particularly along the Manjang, Namhyun and Posunri cave clusters. This implies that there is clear surface migration induced by cave instability. 
(a)

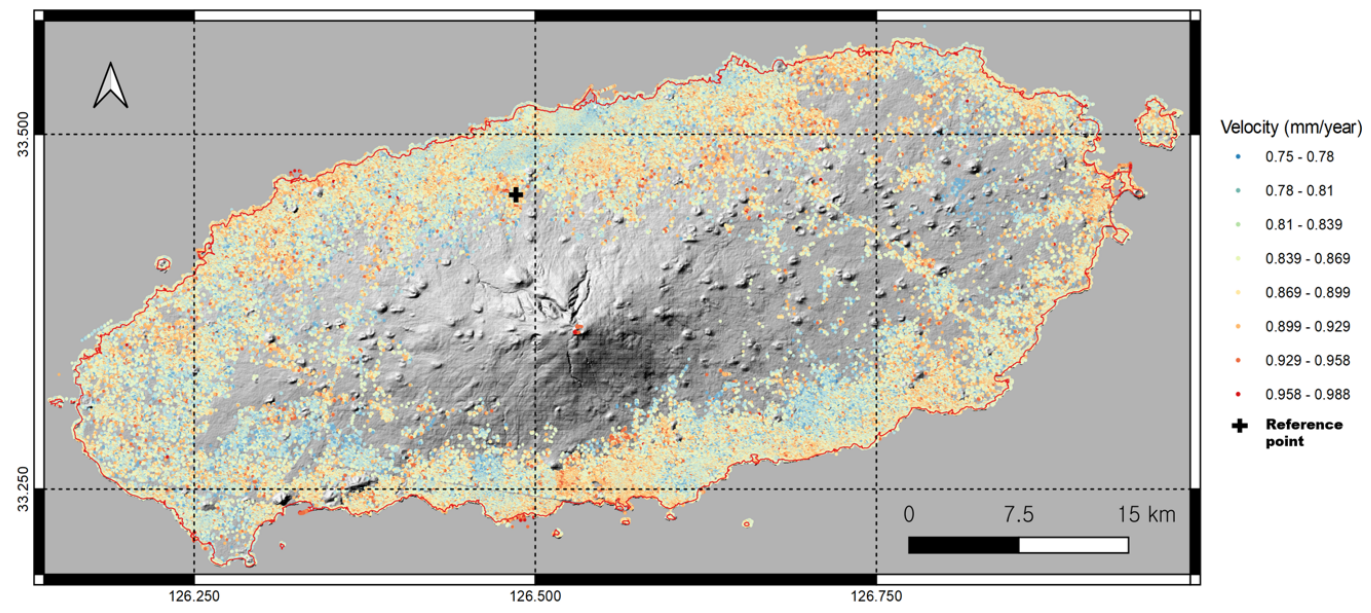

(b)

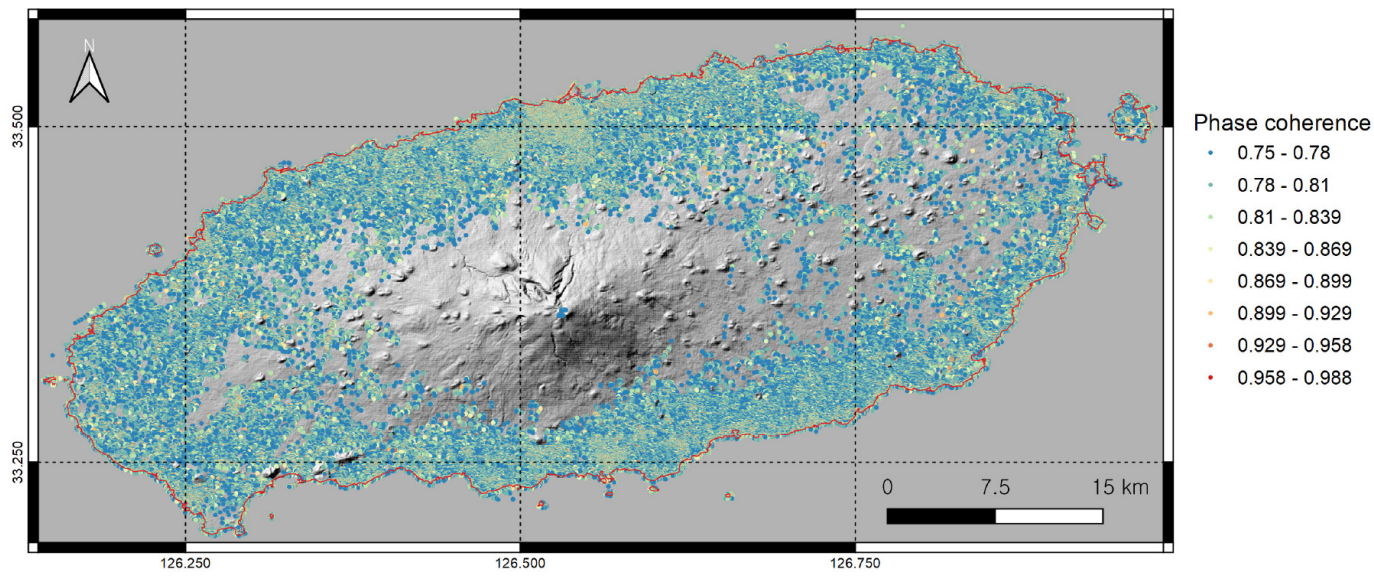

Figure 4: PS processing results over Jeju Island. (a) LOS deformation velocity (mm/year) and (b) average phase coherence.

The outcomes by PS algorithms were further complemented by SBAS technique to manipulate InSAR time series in regional scale. The local deformation was then interpreted together with scatterer behaviours. Since we experienced that SBAS technique is interfered by atmospheric noises, NSBAS technique was employed to improve this performance issue. The 
technical details of SBAS was firstly summarized as follows. The stacked differential interferograms consisting of multiple masters and slaves are constructed. It corresponds to a linear system consisting of a small baseline combination matrix, phase values, and mean phase velocities. Therefore, Singular Value Decomposition (SVD) together with Low Pass (LP) and High Pass (HP) filters are employed on such a linear system to eradicate the spatial and the temporal components of the noise, and to extract the error-reduced deformation. The resultant deformation velocity estimated from such linear operation has excluded the atmospheric, orbital and base DEM noise which are estimated by LP and HP filtering. and changes of topography, mis-registrations and weather conditional changes, lead occasional breaks in connection of correlation covering all observations. Therefore, the inverted deformation by SBAS and/or PS algorithms was limited to provide highly densified observations in InSAR time series analyses to trace regional deformation which may be induced by lava tube networks. Thus an enhanced SBAS technique was required and the modified time series analysis techniques, such as Stanford Method for Persistent Scatterers/Multi-Temporal Interferometry (StaMPS/MTI) (Hooper, 2008) and NSBAS (LópezQuiroz et al., 2009; Doin et al., 2011), were developed. As reported in Gong et al. (2016), among the four different time series InSAR algorithms, including NSBAS, SBAS, StaMPS/MTI, NSBAS is a noted distinguished time series technique because of its significant merit of manipulating partially connected scatterers. It was demonstrated that the NSBAS technique produced superior observation point densities in the target sites. Thus it fits our purpose to observe regional deformation patterns caused by potential lava tube networks. Since the target area is highly fragile against phase delay of atmospheric water vapour created by surrounding sea areas, the atmospheric error in phase difference was essential to be compensated. Although it was usually done by algorithmic bases of PS and SBAS, the introduction of external atmospheric phase screen (APS) data sets and the fusion with atmospheric correction of InSAR time series are more efficient (Nico et al., 2011). European Centre for Mediumrange Weather Forecasts (ECMWF) ERA-Interim (Szczypta et al., 2011) was employed as the source of APS considering the 250 large extend of the target area, as Jolivet et al. (2012) has identified that the effects of such atmospheric phase screen (APS) model employing ECMWF ERA is efficient to compensate time series analysis. Error compensations of each interferogram product were performed by subtracting APSs (Jolivet et al., 2014; Kim et al., 2017; Kim et al., 2018). The orbital error compensation was carried out by the procedures as described in Biggs et al. (2007) and Wang and Jonsson (2014). The orbital inaccuracy caused the image registration errors and its consequent distortions can be approximated by the form of polynomial 255 as:

$f(R, A)=\mathrm{aX}^{2}+b X Y+c Y^{2}+d X+e Y+f$

$\mathrm{X}$ and $Y$ are the range and azimuth respectively, $(a, b, c, d, e)$ is the coefficients which can be found through the least squared solution and $f$ is error residual. By adding this correction component, it is possible to achieve sub-pixel co-registration removing the erroneous mis-registration by the orbital inaccuracy. In this study, we constructed APSs using Generic Atmospheric Correction Online Service (GACOS) service (http://ceg-research.ncl.ac.uk/v2/gacos/) which is created also based on ECMWF 
ERA-Interim model (Yu et al., 2018). Then APSs were applied to each interferogram produced by Centre for the Observation and Modelling of Earthquakes, Volcanoes and Tectonics (COMET) provided by Looking Into Continents from Space with Synthetic Aperture Radar (LICSAR) (Lazecký et al., 2020) service (https://comet.nerc.ac.uk/COMET-LiCS-portal/), and feedforwarded NSBAS routine, LiCSBAS (Morishita et al., 2020).

The outcomes of NSBAS using the interferometric pairs presented in Fig. 2(b) together with its phase coherence values was given in Fig. 5. Note that in PS observations, their phase coherences are in high ranges $(>0.75)$ and the reliability was proved (Fig. 4(b)). However the phase coherences of NSABS are relatively low except for rocky surfaces and urban areas as shown Fig. 5(b). Hence, we employed NSBAS data as an ancillary data rather than a deformation signal of LTDP.
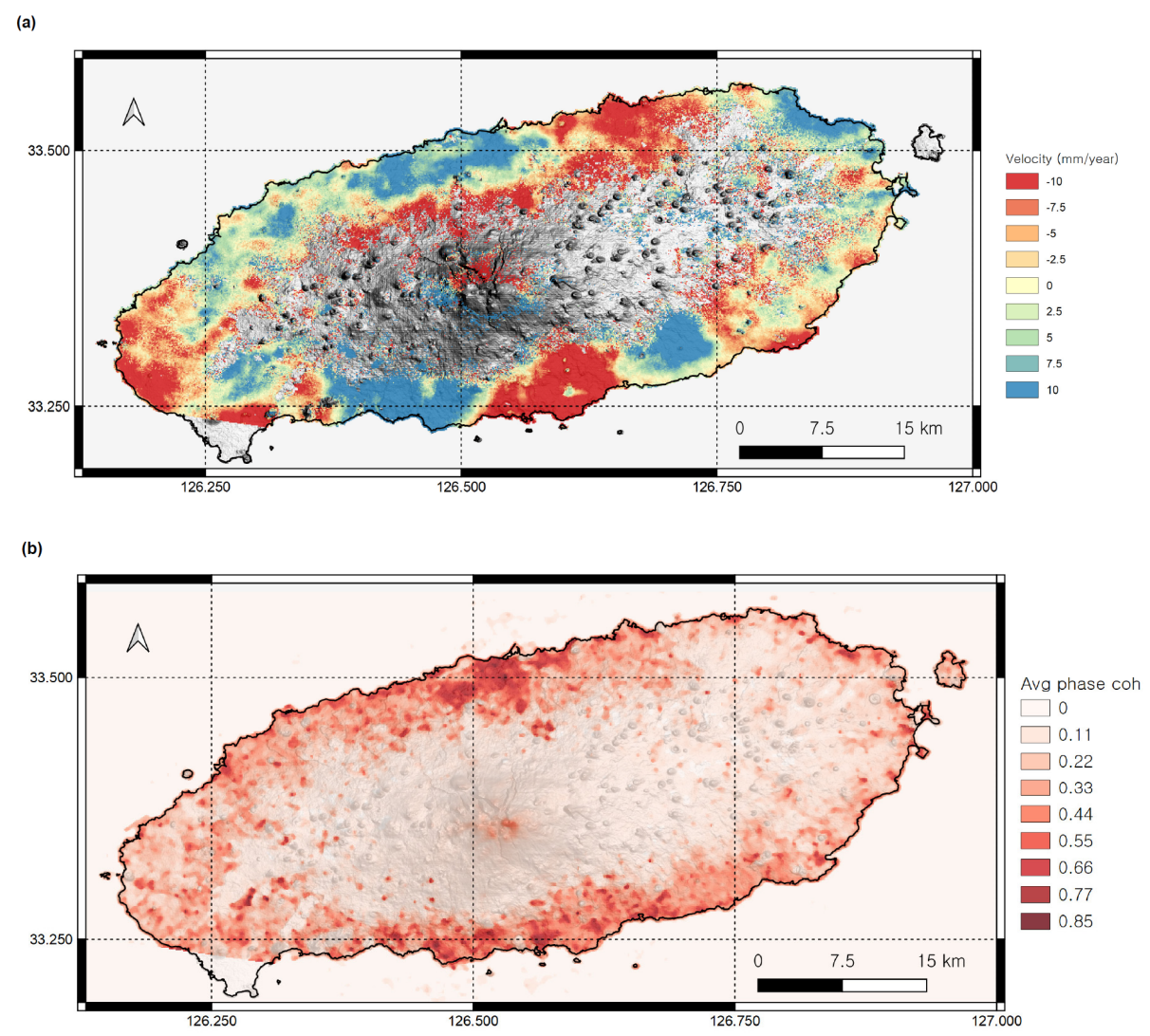

Figure 5: NSBAS processing results over Jeju Island. (a) LOS deformation velocity (mm/year) and (b) average phase coherence. Noted that the phase coherence extracted in NSABS is lower than the coherence in PS processing. 


\section{Interpretation and Discussion}

As PS velocities on the observation points present LOS directional behaviours, PS points were introduced to identify the trail of potential lava tubes and their deformation hazards with proper interpretations. Since the instabilities of lava tube have been identified by the structural analyses employing Finite Element Method (FEM) (Blair et al., 2017; Theinat et al., 2020) or the field work demonstrating the lava tube collapsing (Son, 2009), the surface deformations induced by lava tubes might also be detected by InSAR time series analyses. In addition, the sinkhole detected by InSAR analyses previously performed by Atzori et al. (2015), Baer et al. (2018) and Intrieri et al. (2015) are proposed as comparable study cases as the cavities induced by underground sinkholes and lava tubes would cause similar surface deformations. Although we were able to extract a large number of deformation candidates based on the InSAR analysis results and concepts described above, the technical difficulties to discriminate the potential LTDPs still remain as follows : 1) there are false deformations caused by other factors such as regional subsidence, the thermal dilations and the failures of InSAR algorithms; 2) the definition of LTDP's behaviours is not clear as we do not have precise ground truth; 3) The domains to be tested as target LTDP is enormous because the PS observations included more than 200,000 points all over Jeju Island.

290 To tackle all problems, we introduced machine learning methods. First, we built the training datasets based on the spatial analyses and the geological/demographic contexts. The established ground truth data sets were then feedforwarded to the training stage of proposed machine learning methods. Subsequently we classified all PS target points using trained machine learning platforms. The extracted points as LTDPs were re-analysed in the comparison of background context and validation data sets.

295 In Table 2 and Fig. 6, the standards to define training data sets and their locations were shown. As Son (2009) assigned, the road crossing with lava tubes or the cavities on lava flows often caused the failures of the roof of corresponding lava tubes/cavities. We investigated the deformations patterns of PS observations on road-crossing points with Manjang cave and all Sumgols. We choose Manjang cave as the most deformation fragile case because of the shallow structure of the lava cave (see Fig. 9(a)), extensive length and high interaction with tourist activities. On the contrary, Sumgols was originally created

300 by the vertical failures of lava cavities, and the proximity to roads supposedly indicates the instability and deformations. With 177 InSAR observations (77 on Manjang cave and 100 on Sumgols) in road crossing areas regions, we discovered that the deformation patterns could be classified as 1) minus LOS migrations ( $<-1 \mathrm{~mm} /$ year) which imply vertical subsidence, so called V-migration patterns; 2) positive LOS migrations (>0.75 mm/year) which might refer to horizontal deflections, so called $\mathrm{H}$ migration patterns as consistent uplift deformations are almost impossible especially in rocky surface of lava flow. Thus $50 \mathrm{~V}-$ migrations and $17 \mathrm{H}$-migrations were assigned as the training data. Note that there might be some minus LOS migrations induced by horizontal creep to LOS direction in SAR sensor but this portion in V-migration should be minor as the major contribution to LOS direction is up- and downward deformation (Hu et al., 2014). Interestingly, around Sumgol, the major of deformations (> 70\%) are V-migration, while H-migration in Manjang cave occupied 50\% of deformation points. It fits the 
hypothesis in which vertical failures in Sumgols mainly induce V-migration patterns, but the large cavity such as Manjang produced $\mathrm{H} / \mathrm{V}$-migration pattern together. Therefore, we constructed the training vectors of potential lava tubes combining two V-migrations patterns together. Their behaviours included highly variable signals perhaps involved with seasonal effects as shown in Fig. 7(a) and (b), where changes possibly induced by thermal expansion are noticed in summer time. H-migration patterns were introduced as the secondary indicator of potential instability by lava cavity. The stable PS points with no significant variation were excluded for the input data of machine learning applications. However, we observed that two kinds of deformation patterns might be mis-recognized as the genuine LTDPs. The first one is the deformation induced by regional subsidence, while the other is the structural deformation such as newly built buildings. The regional subsidence is clearly observed in Seowipo sediment perhaps caused by regional condensations (see Fig. 6 and Fig. 1). Therefore the strong minus deformations ( $<-2 \mathrm{~mm} / \mathrm{year}$ ) in Seowipo sediment were chosen as the training vectors of regional subsidence. The stable behavior is shown in Fig. 7(c) in which the variation is quite different from the Smugol-road-crossing or tube-road-crossing regions. The instability of individual structures was chosen on the opposite side of Jeju city areas where large buildings are populated. Since there are a large number of deformations with random changing patterns, the average behaviour is uniform and is shown in Fig. 7(d). Since there are not enough training points, the pattern of H-movement is highly variable (Fig. 7(e)).

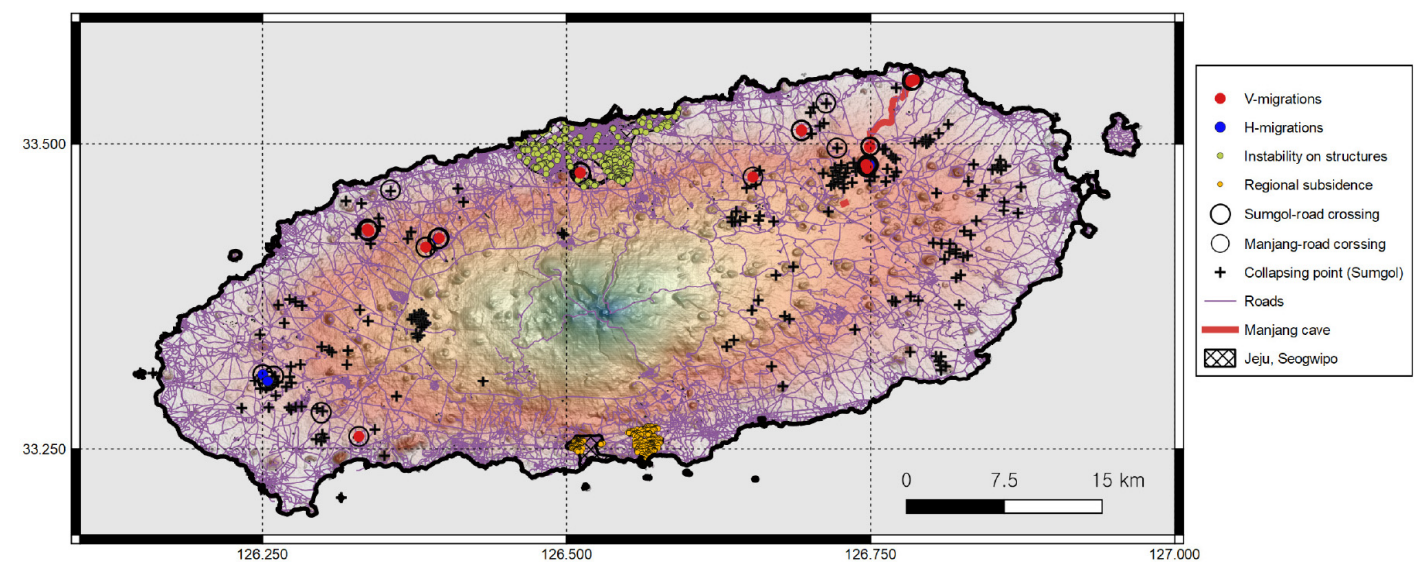

325 Figure 6: Training point locations of V-migration, H-migration, regional subsidence and instability points by artificial structures for machine learning. The training vectors for regional subsidence were chosen in Seogwipo City where Jeju Island's only sediment unit exists. Training vectors for instability caused by artificial structures were built in the Jeju City area, where the largest buildings are concentrated. 
Table 2. The number and standard of training data.

\begin{tabular}{l|c|c|c}
\hline & Number & $\begin{array}{l}\text { Selection standard } \\
\text { (velocity (mm/year) and standard deviation) }\end{array}$ & Constraints \\
\hline V-migrations & 50 & $\begin{array}{c}\text { Velocity }<-1.0 \\
\text { Stddev }>0.5\end{array}$ & $\begin{array}{c}\text { Soumgol and } \\
\text { Manjang cave around } \\
\text { road crossing }\end{array}$ \\
\hline H-migration & 17 & Velocity $>-0.75$ & Soumgol and \\
& & Stddev $>0.5$ & $\begin{array}{c}\text { Manjang cave around } \\
\text { road crossing }\end{array}$ \\
\hline Regional subsidence & 483 & Velocity $<-2$ & Seogwipo sediment \\
& & Stddev $>1.0$ & unit \\
\hline Instability points by artificial & 433 & Velocity $<4.5$ & Stddev $>1.0$ \\
structures & & City area \\
\hline
\end{tabular}
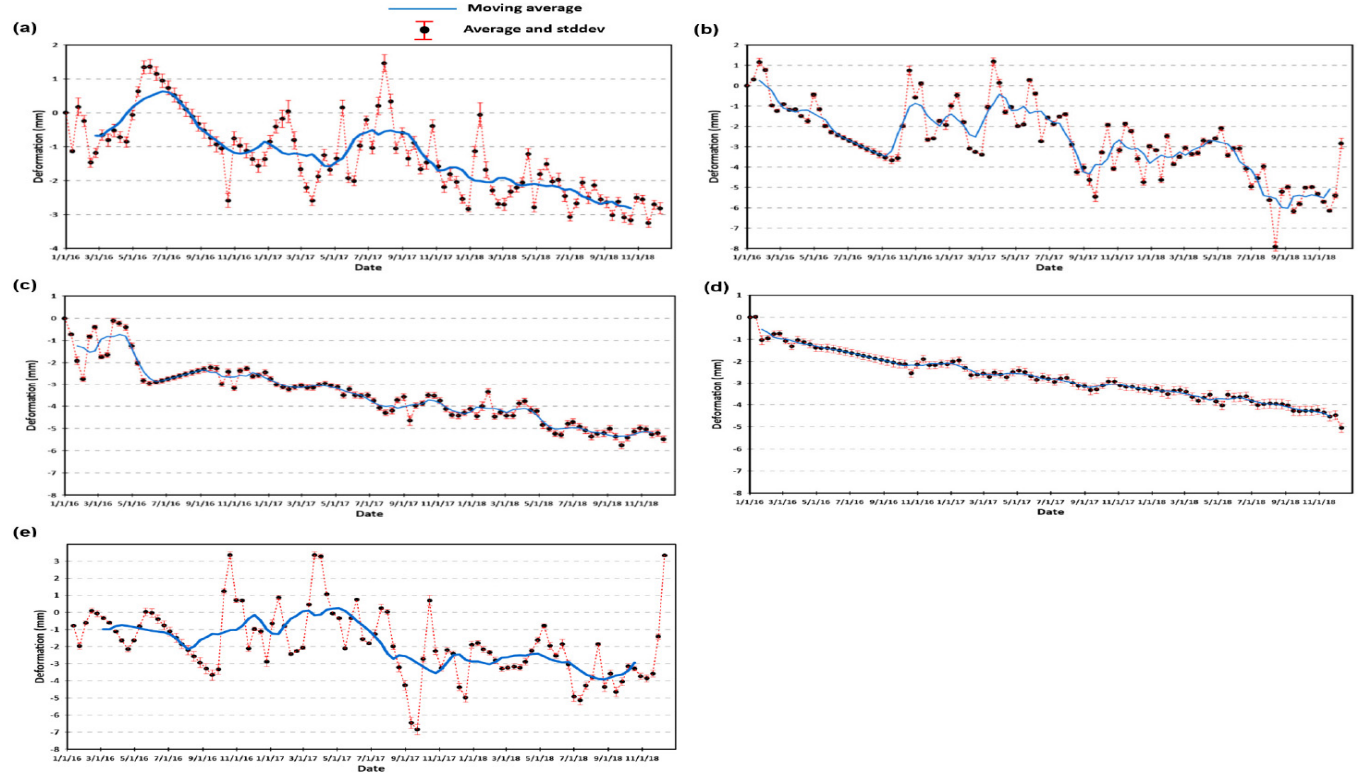

Figure 7: Deformations and standard deviations for training vectors on (a) collapse (Sumgol)-road crossing points, (b) Manjang cave-road crossing points, (c) deformation points in Seogwipo sediments, (d) deformation points in Jeju City urban area and (e) deformations points on H-migrations. 
Once after the training vectors were established, point classification was conducted. We employed two algorithms - random forest (RF) (Ho, 1998; Breiman, 2001) and gradient boosting (GB) (Friedman, 2002; Mason et al., 2000) methods. RF is the use of multiple decision tree construction in the time of training stage and bootstrap aggregation of their outputs as an ensemble method. Thus it is effective to prevent overfitting and to upgrade modelling accuracy. Since Liaw and Wiener (2002) presented its applications for classification, it has been widely used and the capability for manipulating spatial data sets was demonstrated. GB is an algorithm to exploit residual fitting of model as a kind of boosting approach and has been known as the classifier with high precision. We applied both algorithms on PS points screened by the mask through the spatial analyses (see the Section 3.1). As a result, it was observed that the outputs by RF have significant problems to detect $\mathrm{H}$-migrations as only $1 \%$ instability points were classified as H-migrations. Therefore we excluded RF results for further analyses. The detected H/Vmigrations in potential LTDPs using GB algorithm were presented in Fig. 8(a), in which, 1034 V-migrations and 245 Hmigrations were detected. Through an overlaying of the potential LTDPs on the strength of spatial analysis mask, some insight of undiscovered lava tubes were revealed and shown in Fig. 8(a). First, potential LTDPs around Jeju city area might include lots of instability induced by individual building structures rather than the potential lava tubes. The constraints to identify LTDPs on the undiscovered lava tubes are: 1) it should be distributed as a linear form in the direction of lava flow, which is mostly from the cinder cone as the source of lava flows to the coastal line; 2) V/H-migrations must be distributed together; 3) the lava tube networks producing LTDPs might cause regional linear deformation.

Overlaying of H/V-migrations and the NSBAS deformation map is shown in Fig. 8(b). We defined the locations of potential lava networks from group A to $\mathrm{G}$ as assigned ellipses. The major axis of the ellipse is the estimated direction of the involved lava flow. The most interesting and distinguished group is B1, which originated from Gama cinder cone to the coastal area, has well-distinguished V/H-migrations along a significant subsidence corridor of NSBAS deformation. Around Gama cinder cone, there is a $2 \mathrm{~km}$ length underground tunnel which was built by Japanese army during World War II (WWII) and starts to become unstable. Although some unstable points might be caused by the military tunnel, the spatial extent of group B1 is too large to be considered as the consequence of WWII military tunnel. However it is worthwhile noting that more than 700 WWII military tunnels are widely distributed in Jeju Island and a large number of them are in structural failures and/or not discovered. It is the reason we classified the points only within spatial analysis mask defined in section 3.1. Group B2 has also similar contexts, such as a subsidence corridor and flow direction from a cinder cone to coastal line. The other obvious potential LTDP group is A1, which certainly fits with the direction of a Basalt-Trachyte unit (see Fig. 1(b)) and follows the terminus of a lava

365 flow. Since only a small number of lava tubes are identified over there, we proposed an extensive and undisclosed lava tube network over A1. Group A2 is proposed as a lava tube trail as it very well fits with an independent Basalt-Trachyte lava flow unit starting a cinder cone shown in Fig. 1(b). Although the trail of potential LTDPs is not clear, groups D1 and D2 should be noticed as the area will soon be reconstructed to the international airport. Groups E and C are coincided with the trails of two biggest lava tunes, Majang (length $>7.4 \mathrm{~km}$ )-Yunchen (length $>2.4 \mathrm{~km}$ ) cluster and Bilremot (length $>11.7 \mathrm{~km}$ ) cave respectively. The average deformation pattern of detected V-migration shown in Fig. 8(c) is very similar to that of the cave- 
https://doi.org/10.5194/nhess-2020-321

Preprint. Discussion started: 17 October 2020

(c) Author(s) 2020. CC BY 4.0 License.
Natural Hazards and Earth System Sciences

Discussions

road-crossing points in Fig. 7(a) than other training data. The average H-migration pattern in Fig. 8 (d) is quite different from H-migration training vectors but has steady increase as expected.

(a)

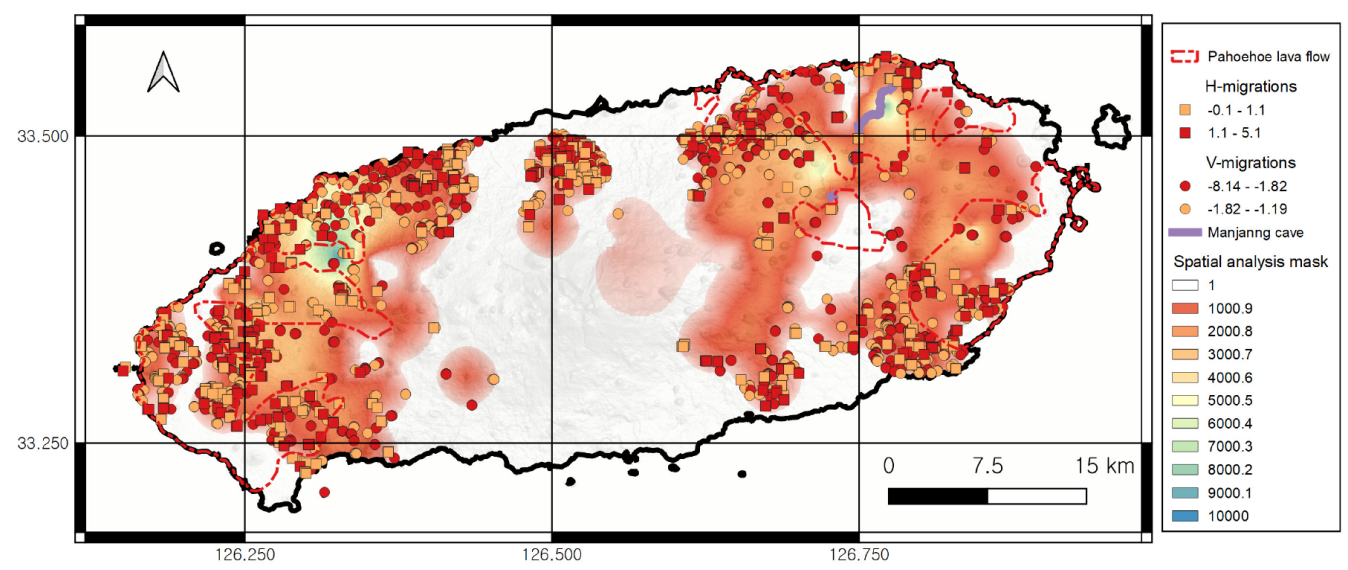

(b)
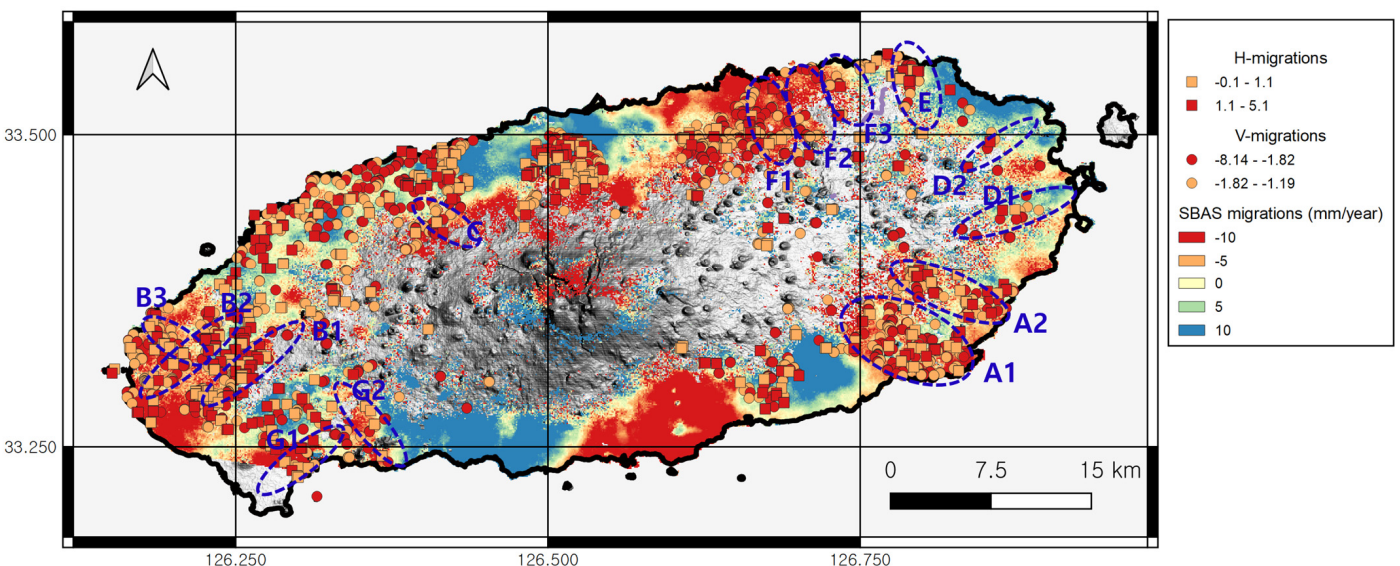


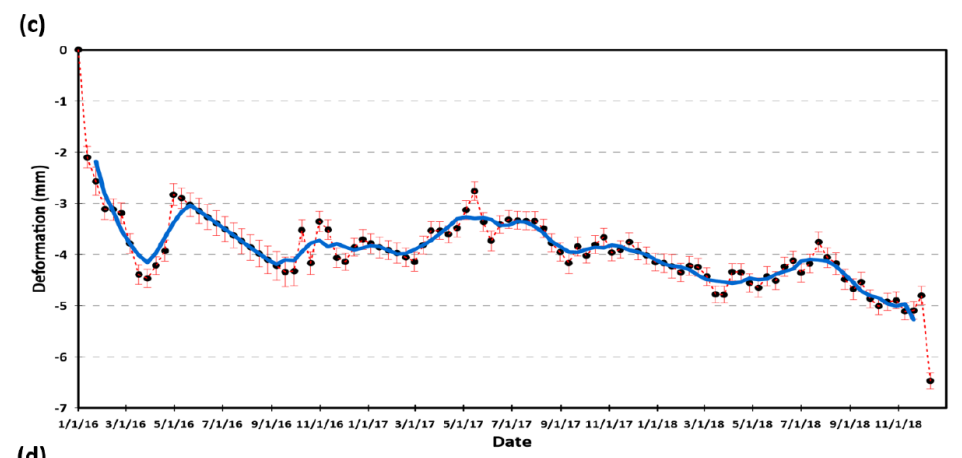

(d)

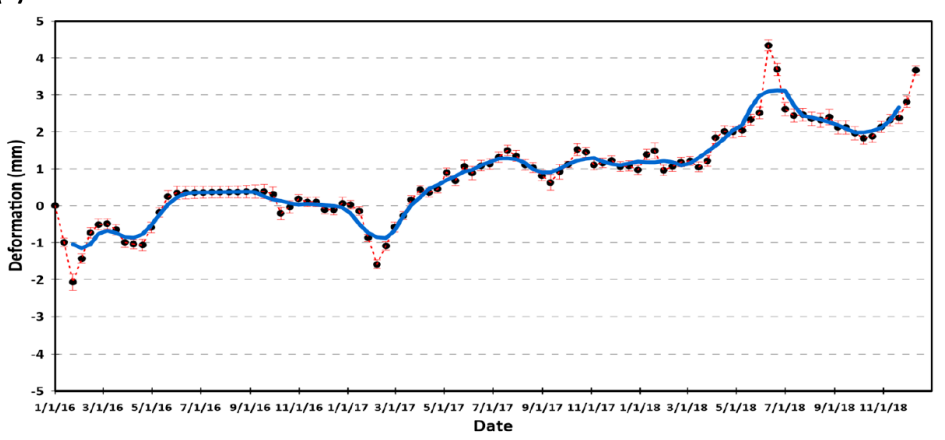

Figure 8: Distribution of LTDPs on (a) spatial analysis mask and Pahoehoe lava flow and (b) SBAS regional deformations together with estimated clusters implying potential lava tube networks. (c) PS average deformation and standard deviation of V-migration points and (d) PS average deformation and standard deviation of H-migration points.

Regarding the instability points around Manjang (E) cave, it is corresponding to the exit of Manjang cave which has shallow double cave structure as shown in Fig. 9(a). Groups F1-F3 demonstrates the high density of potential LTDPs and alignment with lava flow directions from cinder cones to coastal line. Groups G1 and G2 are ambiguous as their alignments do not fit with lava flow directions in that area. Although regional subsidence and/or alignment with corresponding lava flow was not observed, a constant attention of the potential LTDP distribution in north-eastern side is still required. Along the north western coastal line, there are some lava tubes which are in collapsing risks due to their shallow cavity and proximity to road-crossing (see the Geamcheon and Gamnamdap caves shown in the laser scanned data respectively given in Fig. 9(b) and (c)). The potential LTDP distributions in the north western coastal line are only limited along the coastal line and irregularly distributed. This could be explained by the deeply-incised caves in inland side to limit the InSAR observation capability in comparison to Geamcheon and Gamnapdap caves. Note that the deep incised caves are located in the inland area from Geamcheon cave. The 
issue now being raised is whether these 3D cave structures make deformations as observed in InSAR analyses. Since numerical modelling, for instance the FEM using 3D cave data and estimated tensile stress, is beyond the scope of this study, clues can be found in precedent studies regarding tunnel stability. In particular, Yang and Long (2015) established the relationship between the dimensions of collapsing parts which are defined with L1, L2 and radius R on circularly approximated cavity (see 395 Fig. 9 (d)), stresses and material properties. Thus the displacement induced by collapse will be dominated by the vertical way but mixed with the horizontal deformations which are applied symmetrically at the centre of the approximated circular as shown in Abdellah et al. (2018). Therefore H-migrations detected by PS InSAR mainly contained part of horizontal deformations directed toward the SAR sensor, whereas the detected V-migrations represented mainly vertical deformations combining horizontal deformations away from SAR sensor position. The magnitude of deformations around circular tunnels 400 are very much different according to the applied tensile stress, materials properties (hard/soft rocks and soil) and the dimension of tunnel. If the tunnel depths are limited to very shallow $(<10-20 \mathrm{~m})$, the deformation values calculated in the case studies vary from sub-millimetre depending on the scenarios (Paternesi et al., 2017; Abdellah et al., 2018; Zhang and Li, 2009). However, the fractures in the weathering wall of the lave tubes and the relatively weak brittle strength of basaltic rocks combined with anthropogenic stresses certainly cause sufficiently high deformations which can be detected by InSAR

405 observations.

InSAR LOS migrations can be expressed using the quantities in Fig. 9 (d) and the relationship by Fialko et al. (2001) as

$\operatorname{disp}_{\text {los }}=-\sin \theta \cos \alpha \operatorname{disp}_{h}+\cos \theta \operatorname{disp}_{v}$

410 where disp $_{\text {los }}$ is LOS displacement, $\operatorname{disp}_{h}$, and $\operatorname{disp}_{v}$ are horizontal and vertical displacements, $\theta$ represents the incidence angles and $\alpha$ is the heading angle.

Thus, the observed disp los can be estimated using the angles in Table 1 and eq. (4) in the case of Fig. 9 (d).

H-migration $=0.694 d_{h}-0.719 d_{v}$

$415 \quad$-migration $=-0.694 d_{h}-0.719 d_{v}$

It explains the relatively small $\mathrm{H}$-migrations compared to the V-migrations even on the same cavities. 
(a)

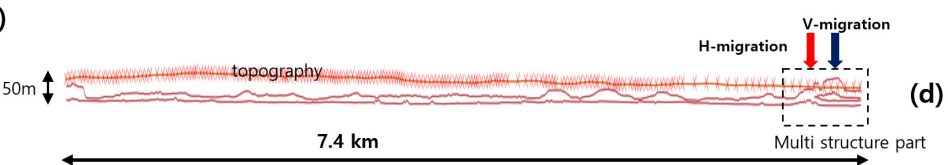

(b)
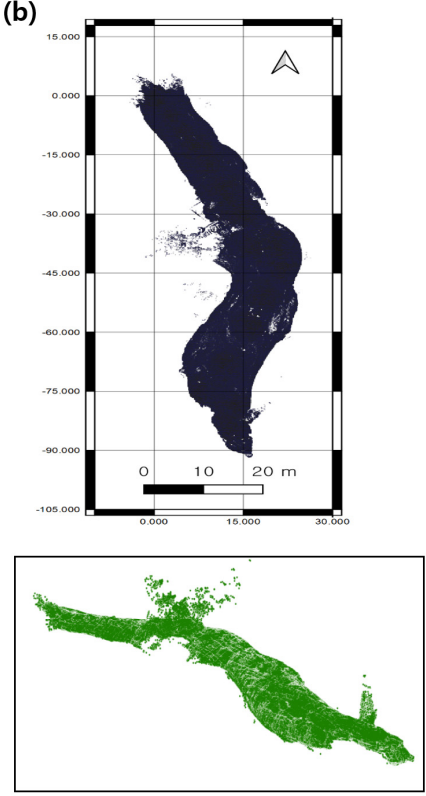

(c)

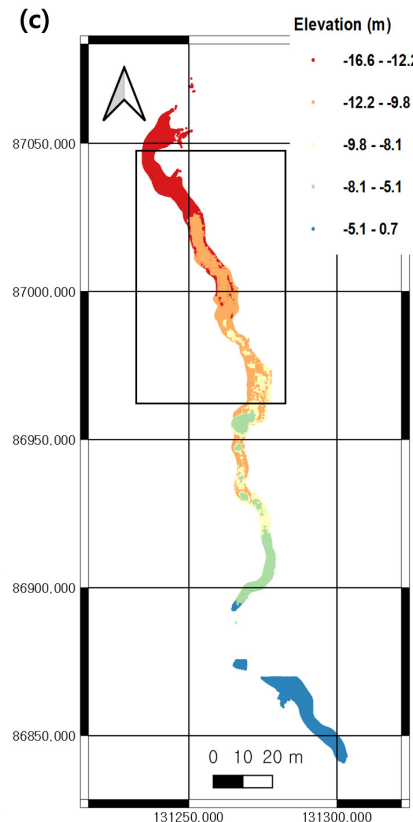

(d)

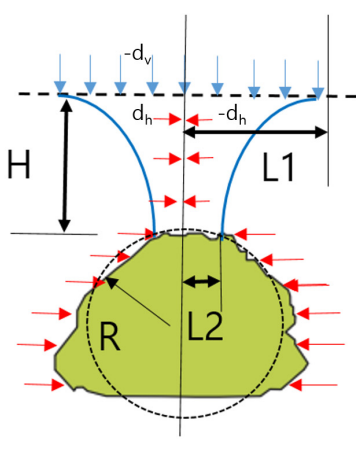

Direction of collapsing $\checkmark$ displacement

$\longleftarrow \quad$ Direction of horizontal displacement

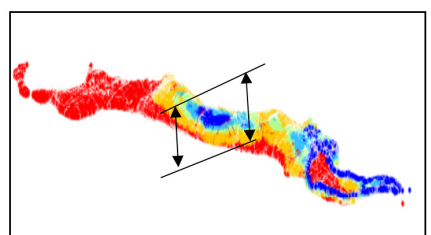

- $-13.415100--11.968700$

$-11.968699--11.374300$
-

$-11.192099--11.006800$

$-11.006799--10.854600$

Figure 9: Examples of 2D/3D caves models and instability check. (a) The 2D profile of Manjang caves and the location of detected LTDPs on the terminus of tube which is taken from Ahn and Hwang (2009). (b) 3D LiDAR map in Geamcheon cave as a typical collapsing cave around road cross. Note the elevations in this cave range from 1-3 meter above mean sea level. (c) 3D LiDAR map in Gamnamdap cave with thin topography. (d) The diagram of expected deformations on cross sectional lava tube (H: depth of cave, R: Radius of approximated circular on lava tube, L1 and L2: the lengths of upper and lower parts of collapsing part, $\mathrm{d}_{\mathrm{h}}$ and $\mathrm{d}_{\mathrm{v}}$ : hypothesized $\mathrm{H} / \mathrm{V}$ deformations at certain collapsing points). Refer Fig. 10 to identify cave locations.

After all, we identified a group of potential LTDPs using InSAR observation and spatial analyses. To prove the reliability of this approach, we employed road-crossing survey by Son (2016) to measure the known collapses of lava tubes. Among 27 ongoing collapses of lava tubes in this survey, 14 caves have LTDP within the buffer zones built by their length and 7 of them have both $\mathrm{H}-\mathrm{V}$ migrations (referred to Fig. 10). 


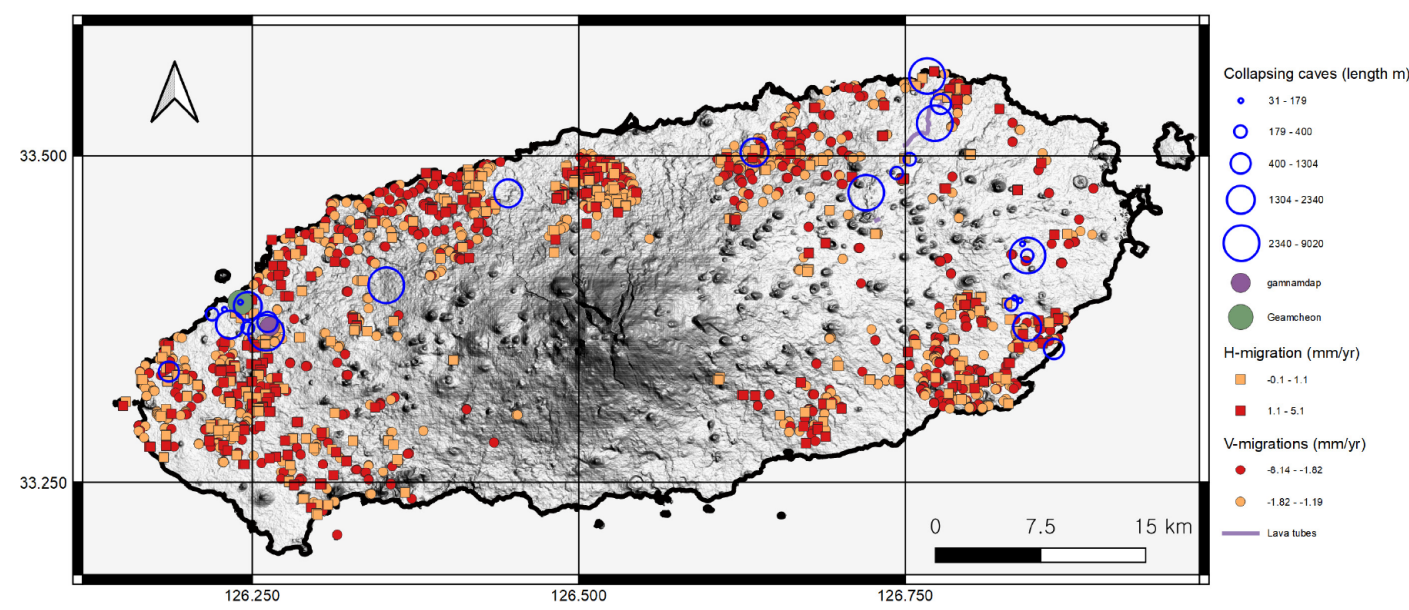

Figure 10: The distribution of detected deformations and the buffer zones around collapsing lava tubes. Buffer zone was given by the cave length.

Considering some deep instabilities which would not be revealed as the surface topographic deformations, the estimated PS measurement in this study is capable of discriminating LTDP with considerable accuracy. However, the concern remained unsolved in this study is to eradicate the false/pseudo LTDPs which can lead to wrong conclusions regarding the spatial distribution of lava tube networks. The detailed validation using planned GPS and InSAR survey, or perhaps employing corner reflector to be synchronized observation is necessary in the future study.

\section{Conclusions}

The geological importance of lava tube in Jeju Island has been noticed with the discovery of exterritorial lava tubes in Moon (Kaku et al., 2017), Mars (McGown et al., 2002), Io (Schenk and Williams, 2004) and their habitable environments. However the risk caused by such geological environment is not regularly monitored. Being a testbed of risk assessment, the lava tubes and the undisclosed lava tube networks in Jeju Island have been investigated. Along with the construction of the second international airport located in western Jeju, a significant concern on the risk imposed by the instability of the hidden lava tube network was raised. To address the issue, this study conducted InSAR campaign and subsequent machine learning applications together with spatial analyses of geological contexts. The discovered LTDPs demonstrated a plausible distribution to be classified as the instabilities on the undiscovered lava tube networks based on their peculiar patterns confined on thin corridors 
and deformation behaviours. However, some false/pseudo LTDPs still remained due to the instabilities by other artificial structures and regional condensations.

The lessons learned from this study are summarized as follows. First, the study elucidates a procedure to spot shallow lava tube networks and their imposing risks. However, the outcomes also demonstrate that the demand to fuse ground works such as GPS and corner reflector over suspected deformations to clarify InSAR outcome. The future InSAR missions with the better penetration depth such as L-band NASA-ISRO Synthetic Aperture Radar (NiSAR) (Alvarez-Salazar et al., 2014) and P-band BIOMASS missions (Scipal et al., 2010) will be greatly useful as those can detect subsurface deformation signals. The combination with structural analyses to classify InSAR signals using estimated instability is a highly useful approach and will be the destination of future improvement of this study. Second, beside the proposed/existing methods to discover terrestrial/extra-terrestrial lava tunes, such gravitation data sets (Chappaz et al., 2017), ground penetrating radar (Kaku et al., 2017), morphological analyses and spotting of skylight (Cushing et al., 2007; Whittaker, 2012), we proved InSAR survey is an effective tool to detect lava tube networks. Considering proposed planetary InSAR missions (Carrer et al., 2018; Rosen et al., 2001; Ghail et al., 2016; Kim et al., 2015), it has the potential to be applied to lava tubes on the planetary surface.

Code/Data availability: The data that support the findings of this study are available on request from the corresponding author.

Author contribution: JRK designed this research and performs key interpretations together with corresponding writing. SYL conducted PS analysis and corresponding writing. JWO complied the relevant data sets and wrote geological background part.

\section{Acknowledgements}

We acknowledge the on-line InSAR processing tool, LiCSAR, which contains modified Copernicus Sentinel data analysed by the Centre for the Observation and Modelling of Earthquakes, Volcanoes and Tectonics (COMET). LiCSAR uses JASMIN, the UK's collaborative data analysis environment (http://jasmin.ac.uk). The second author would like to thank the financial support from the Ministry of Science and Technology, Taiwan (Grant number: MOST 106-2420-H-004-015-MY3 and MOST 109-2625-M-004-002).

\section{Competing interests}

The authors declare that they have no conflict of interest.

\section{References}

Abdellah, W. R., Ali, M. A., and Yang, H.-S.: Studying the effect of some parameters on the stability of shallow tunnels, J. Sustainable Min., 17, 20-33, 2018. 
Ahn, U.-S., and Hwang, S.-K.: Study on source of lava flows forming the Manjanggul lava tube, The Journal of the Petrological Society of Korea, 18, 237-253, 2009.

Alvarez-Salazar, O., Hatch, S., Rocca, J., Rosen, P., Shaffer, S., Shen, Y., Sweetser, T., and Xaypraseuth, P.: Mission design for NISAR repeat-pass Interferometric SAR, Sensors, Systems, and Next-Generation Satellites XVIII, 2014, 92410C,

Atzori, S., Baer, G., Antonioli, A., and Salvi, S.: InSAR-based modeling and analysis of sinkholes along the Dead Sea coastline, Geophys. Res. Lett., 42, 8383-8390, 2015.

Baer, G., Magen, Y., Nof, R., Raz, E., Lyakhovsky, V., and Shalev, E.: InSAR measurements and viscoelastic modeling of sinkhole precursory subsidence: Implications for sinkhole formation, early warning, and sediment properties, J. Geophys. Res. Earth Surf., 123, 678-693, 2018.

Berardino, P., Fornaro, G., Lanari, R., and Sansosti, E.: A new algorithm for surface deformation monitoring based on small baseline differential SAR interferograms, IEEE Geosci. Remote. Sens. Lett., 40, 2375-2383, 2002.

495 Biggs, J., Wright, T., Lu, Z., and Parsons, B.: Multi-interferogram method for measuring interseismic deformation: Denali Fault, Alaska, Geophys. J. Int., 170, 1165-1179, 2007.

Blair, D. M., Chappaz, L., Sood, R., Milbury, C., Bobet, A., Melosh, H. J., Howell, K. C., and Freed, A. M.: The structural stability of lunar lava tubes, Icarus, 282, 47-55, 10.1016/j.icarus.2016.10.008, 2017.

Breiman, L.: Random forests, Mach. Learn., 45, 5-32, 2001.

500 Brenna, M., Cronin, S. J., Nemeth, K., Smith, I. E., and Sohn, Y. K.: The influence of magma plumbing complexity on monogenetic eruptions, Jeju Island, Korea, Terra Nova, 23, 70-75, 2011.

Brenna, M., Cronin, S. J., Smith, I. E., Maas, R., and Sohn, Y. K.: How small-volume basaltic magmatic systems develop: a case study from the Jeju Island Volcanic Field, Korea, J. Petrol., 53, 985-1018, 2012 a.

Brenna, M., Cronin, S. J., Smith, I. E., Sohn, Y. K., and Maas, R.: Spatio-temporal evolution of a dispersed magmatic system and its implications for volcano growth, Jeju Island Volcanic Field, Korea, Lithos, 148, 337-352, 2012b.

Bussey, D., Guest, J., and Sørensen, S. A.: On the role of thermal conductivity on thermal erosion by lava, J. Geophys. Res. Planets, 102, 10905-10908, 1997.

Calvari, S., and Pinkerton, H.: Formation of lava tubes and extensive flow field during the 1991-1993 eruption of Mount Etna, J. Geophys. Res. Earth Surf., 103, 27291-27301, 10.1029/97jb03388, 1998.

510 Carrer, L., Gerekos, C., and Bruzzone, L.: A multi-frequency radar sounder for lava tubes detection on the Moon: Design, performance assessment and simulations, Planet. Space Sci., 152, 1-17, 10.1016/j.pss.2018.01.011, 2018. 
Chappaz, L., Sood, R., Melosh, H. J., Howell, K. C., Blair, D. M., Milbury, C., and Zuber, M. T.: Evidence of large empty lava tubes on the Moon using GRAIL gravity, Geophys. Res. Lett., 44, 105-112, 10.1002/2016g1071588, 2017.

Crosetto, M., Monserrat, O., Cuevas-González, M., Devanthéry, N., Crippa, B., and Sensing, R.: Persistent scatterer interferometry: A review, ISPRS J. Photogramm. Remote Sens., 115, 78-89, 2016.

Cushing, G., Titus, T. N., Wynne, J. J., and Christensen, P.: THEMIS observes possible cave skylights on Mars, Geophys. Res. Lett., 34, 2007.

Doin, M.-P., Guillaso, S., Jolivet, R., Lasserre, C., Lodge, F., Ducret, G., and Grandin, R.: Presentation of the small baseline NSBAS processing chain on a case example: the Etna deformation monitoring from 2003 to 2010 using Envisat data, Proceedings of the Fringe symposium, 2011, 3434-3437,

Ferretti, A., Prati, C., and Rocca, F.: Nonlinear subsidence rate estimation using permanent scatterers in differential SAR interferometry, IEEE Geosci. Remote. Sens. Lett., 38, 2202-2212, 2000.

Ferretti, A., Prati, C., and Rocca, F.: Permanent scatterers in SAR interferometry, IEEE Geosci. Remote. Sens. Lett., 39, 8-20, 2001.

525 Fialko, Y., Simons, M., and Agnew, D.: The complete (3-D) surface displacement field in the epicentral area of the 1999 Mw7. 1 Hector Mine earthquake, California, from space geodetic observations. Geophys. Res. Lett., 28, 3063-3066, 2001.

Friedman, J. H.: Stochastic gradient boosting, Comput. Stat. Data Anal., 38, 367-378, 2002.

Geudtner, D., Torres, R., Snoeij, P., Davidson, M., and Rommen, B.: Sentinel-1 system capabilities and applications, 2014 IEEE Geoscience and Remote Sensing Symposium, 2014, 1457-1460,

530 Ghail, R., Wilson, C. F., and Widemann, T.: EnVision M5 venus orbiter proposal: Opportunities and challenges, DPS, 2016, 216.208,

Gong, W., Thiele, A., Hinz, S., Meyer, F. J., Hooper, A., and Agram, P.: Comparison of small baseline Interferometric SAR processors for estimating ground deformation, Remote Sens., 8, 330, 2016.

Greeley, R.: Observations of actively forming lava tubes and associated structures, Hawaii, NASA technical memorandum, 1971.

Greeley, R.: Additional observations of actively forming lava tubes and associated structures, Hawaii, Mordern Geology, 3, 157-160, 1972.

Greeley, R.: The role of lava tubes in Hawaiian volcanoes, US Geol. Surv. Prof. Pap, 1350, 1589-1602, 1987.

Hamm, S.-Y., Cheong, J.-Y., Jang, S., Jung, C.-Y., and Kim, B.-S.: Relationship between transmissivity and specific capacity in the volcanic aquifers of Jeju Island, Korea, J. Hydrol., 310, 111-121, 2005. 
Ho, T. K.: The random subspace method for constructing decision forests, IEEE PAMI, 20, 832-844, 1998.

Hooper, A., Zebker, H., Segall, P., and Kampes, B.: A new method for measuring deformation on volcanoes and other natural terrains using InSAR persistent scatterers, Geophys. Res. Lett., 31, 2004.

Hooper, A.: A multi-temporal InSAR method incorporating both persistent scatterer and small baseline approaches, Geophys. 545 Res. Lett., 35, 2008.

Hu, J., Li, Z., Ding, X., Zhu, J., Zhang, L., and Sun, Q.: Resolving three-dimensional surface displacements from InSAR measurements: A review, Earth-Sci. Rev., 133, 1-17, 2014.

Huang, C. T., and Mitchell, O. R.: A Euclidean distance transform using grayscale morphology decomposition, IEEE PAMI, 443-448, 1994.

550 Hwang, S., Ahn, U., Lee, M., and Yun, S.: Formation and internal structures of the Geomunorm Lava Tube System in the northeastern Jeju Island, J. Geol. Soc. Korea, 41, 385-400, 2005.

Intrieri, E., Gigli, G., Nocentini, M., Lombardi, L., Mugnai, F., Fidolini, F., and Casagli, N.: Sinkhole monitoring and early warning: An experimental and successful GB-InSAR application, Geomorphology, 241, 304-314, 2015.

Jolivet, R., Lasserre, C., Doin, M. P., Guillaso, S., Peltzer, G., Dailu, R., Sun, J., Shen, Z. K., and Xu, X.: Shallow creep on the Haiyuan fault (Gansu, China) revealed by SAR interferometry, J. Geophys. Res. Solid Earth, 117, 2012.

Jolivet, R., Agram, P. S., Lin, N. Y., Simons, M., Doin, M. P., Peltzer, G., and Li, Z.: Improving InSAR geodesy using global atmospheric models, J. Geophys. Res. Solid Earth, 119, 2324-2341, 2014.

Kaku, T., Haruyama, J., Miyake, W., Kumamoto, A., Ishiyama, K., Nishibori, T., Yamamoto, K., Crites, S. T., Michikami, T., Yokota, Y., Sood, R., Melosh, H. J., Chappaz, L., and Howell, K. C.: Detection of Intact Lava Tubes at Marius Hills on the Moon by SELENE (Kaguya) Lunar Radar Sounder, Geophys. Res. Lett., 44, 10,155-110,161, 10.1002/2017g1074998, 2017.

Kempe, S.: Principles of pyroduct (lava tunnel) formation, Proceedings of the 15th International Congress of Speleology, 2009, 668-674,

Kempe, S., Bauer, I., Bosted, P., Coons, D., and Elhard, R.: Inflationary versus crusted-over roofs of pyroducts (lava tunnels), Proceedings 14th International Symposium on Vulcanospeleology, 2010, 93,

565 Kempe, S., and Woo, K. S.: Geological observations in pyroducts of Jeju Island, 17th Symposium of Vulcanospeleology, Proceedings, Hawaii 2016 2016,

Kerr, R. C.: Thermal erosion by laminar lava flows, J. Geophys. Res. Solid Earth, 106, 26453-26465, 10.1029/2001jb000227, 2001.

KIGAM (Korea Institute of Geoscience and Mineral Resources): Explanatory Note of Jeju Geological map, 2000. 
Kim, I., and Lee, D.: Magnetostratigraphy and AMS of the Seoguipo Formation and Seoguipo Trachyte of Jeju Island, J. Geol. Soc. Korea, 36, 163-180, 2000.

Kim, J.-H.: Creation Process and Specialty of Volcanic Caves in Jeju, Journal of the Speleological Society of Korea, 45-46, 2006.

Kim, J.-R., Sumantyo, J., and Lin, S.-Y.: Preliminary study for the long wavelength planetary SAR sensor design and applications, EGUGA, 8446, 2015.

Kim, J.-R., Lin, S.-Y., Yun, H.-W., Tsai, Y.-L., Seo, H.-J., Hong, S., and Choi, Y.: Investigation of potential volcanic risk from mt. Baekdu by dinsar time series analysis and atmospheric correction, Remote Sens., 9, 138, 2017.

Kim, J. R., Yun, H., Van Gasselt, S., and Choi, Y.: Error-Regulated Multi-Pass DInSAR Analysis for Landslide Risk Assessment, Photogramm. Eng. Remote Sensing, 84, 189-202, 2018.

580 Kim, Y. S., and Choi, S. H.: Plagioclase-rich nodules in Taeheungri basalt from Namwon, Jeju Island and its implications for tholeiite magmatism, J. Geol. Soc. Korea, 48, 313-324, 2012.

Koh, G.-W., Park, J.-B., and Park, Y.-S.: The Study on Geology and Volcanism in Jeju Island (I): Petrochemistry and 40Ar/39Ar Absolute ages of the Subsurface Volcanic Rock Cores from Boreholes in the Eastern Lowland of Jeiu Island, Econ. Environ. Geol., 41, 93-113, 2008.

585 Koh, G.-W., and Park, J.-B.: The Study on Geology and Volcanism in Jeju Island (III): Early Lava Effusion Records in Jeju Island on the Basis of 40Ar/39Ar Absolute Ages of Lava Samples, Econ. Environ. Geol., 43, 163-176, 2010a.

Koh, G.-W., and Park, J.-B.: The Study on geology and volcanism in Jeju Island (II): Petrochemistry and 40Ar/39Ar absolute ages of the volcanic rocks in Gapado-Marado, Jeju Island, Econ. Environ. Geol., 43, 53-66, 2010b.

Koh, G. W., Park, J. B., Kang, B.-R., Kim, G.-P., and Moon, D. C.: Volcanism in Jeju Island, 49, 209-230, 2013.

Lazecký, M., Spaans, K., González, P. J., Maghsoudi, Y., Morishita, Y., Albino, F., Elliott, J., Greenall, N., Hatton, E., and Hooper, A.: LiCSAR: An Automatic InSAR Tool for Measuring and Monitoring Tectonic and Volcanic Activity, Remote Sens., 12, 2430, 2020.

Liaw, A., and Wiener, M.: Classification and regression by randomForest, R news, 2, 18-22, 2002.

López-Quiroz, P., Doin, M.-P., Tupin, F., Briole, P., and Nicolas, J.-M.: Time series analysis of Mexico City subsidence constrained by radar interferometry, J. Appl. Geophy., 69, 1-15, 2009.

Mason, L., Baxter, J., Bartlett, P. L., and Frean, M. R.: Boosting algorithms as gradient descent, Adv Neural Inf Process Syst, $2000,512-518$ 
McGown, R. D., York, C. L., Billings, T. L., and Walden, B.: Lavatube Entrance Amelioration on the Moon and Mars, in: Space 2002 and Robotics 2002, 155-161, 2002.

Morishita, Y., Lazecky, M., Wright, T. J., Weiss, J. R., Elliott, J. R., and Hooper, A.: LiCSBAS: An Open-Source InSAR Time Series Analysis Package Integrated with the LiCSAR Automated Sentinel-1 InSAR Processor, Remote Sens., 12, 424, 2020.

Nico, G., Tomé, R., Catalão, J., and Miranda, P. M.: On the use of the WRF model to mitigate tropospheric phase delay effects in SAR interferograms, IEEE Geosci. Remote. Sens. Lett. 49, 4970-4976, 2011.

Paternesi, A., Schweiger, H. F., and Scarpelli, G.: Numerical analyses of stability and deformation behavior of reinforced and unreinforced tunnel faces, Comput. Geotech., 88, 256-266, 2017.

Rosen, P., Paillou, P., Hensley, S., Massonnet, D., and Thompson, T.: Imaging Radar Interferometry for the Exploration of Mars, AGUFM, 2001, P52A-0571, 2001.

Schenk, P. M., and Williams, D. A.: A potential thermal erosion lava channel on Io, Geophys. Res. Lett., 31, 10.1029/2004g1021378, 2004

Scipal, K., Arcioni, M., Chave, J., Dall, J., Fois, F., LeToan, T., Lin, C.-C., Papathanassiou, K., Quegan, S., and Rocca, F.: The BIOMASS mission-An ESA Earth Explorer candidate to measure the BIOMASS of the earth's forests, 2010 IEEE international geoscience and remote sensing symposium, 2010, 52-55,

Sohn, Y. K., and Park, K. H.: Early-stage volcanism and sedimentation of Jeju Island revealed by the Sagye borehole, SW Jeju Island, Korea, Geosci. J., 8, 73, 2004.

Son, H.: Geophysical Exploration Report Around Manjanggul Cave, Pai Chai University, 2009.

Son, I..: A Study on the Stability of Lava Cave in Jeju Island, Jornal of Korean Speleology, 108, 1, 2016.

Son, I.: Jeju Island Natural Cave Exploration·Investigation·Research Report, Cultural Heritage Administration, 5-12, 2019.

Szczypta, C., Calvet, J.-C., Albergel, C., Balsamo, G., Boussetta, S., Carrer, D., Lafont, S., and Meurey, C.: Verification of the new ECMWF ERA-Interim reanalysis over France, Hydrol. Earth Syst. Sci., 15, 647, 2011.

Theinat, A. K., Modiriasari, A., Bobet, A., Melosh, H. J., Dyke, S. J., Ramirez, J., Maghareh, A., and Gomez, D.: Lunar lava tubes: Morphology to structural stability, Icarus, 338, 10.1016/j.icarus.2019.113442, 2020.

Valerio, A., Tallarico, A., and Dragoni, M.: A model for the formation of lava tubes by the growth of the crust from the levees, J. Geophys. Res. Solid Earth, 115, 10.1029/2009jb006598, 2010. 
https://doi.org/10.5194/nhess-2020-321

Preprint. Discussion started: 17 October 2020

(C) Author(s) 2020. CC BY 4.0 License.

Wang, T., and Jonsson, S.: Phase-Ramp reduction in interseismic interferograms from pixel-offsets, IEEE J. Sel. Top. Appl. Earth Obs. Remote Sens., 7, 1709-1718, 2014.

Whittaker, W.: Technologies enabling exploration of skylights, lava tubes and caves, NASA Innovative Advanced Concepts (NIAC) Phase I 2012.

630 Witter, J. B., and Harris, A. J. L.: Field measurements of heat loss from skylights and lava tube systems, J. Geophys. Res. Solid Earth, 112, 10.1029/2005jb003800, 2007.

Woo, K., Kim, L., Ji, H., Jeon, Y., Ryu, C. G., and Wood, C.: Geological Heritage Values of the Yongcheon Cave (Lava Tube Cave), Jeju Island, Korea, Geoheritage, 11, 615-628, 2019.

Yang, X.-1., and Long, Z.-x.: Roof collapse of shallow tunnels with limit analysis method, Journal of Central South University, 22, 1929-1936, 2015.

Yu, C., Li, Z., Penna, N., and Crippa, P. J. E.: Generic Atmospheric Correction Online Service for InSAR (GACOS), EGU General Assembly Conference, 2018, 11007,

Yun, H.-W., Kim, J.-R., Yoon, H., Choi, Y., and Yu, J.: Seismic Surface Deformation Risks in Industrial Hubs: A Case Study from Ulsan, Korea, Using DInSAR Time Series Analysis, Remote Sens., 11, 1199, 2019.

640 Zhang, Y., and Li, X.: Finite element analysis of the stability of tunnel surrounding rock with weak rock layer, Mod. Appl. Sci., 3, 22-27, 2009. 